\title{
Occupational Outcomes and Revision Rates for Medial Unicondylar Knee Arthroplasty in U.S. Military Servicemembers
}

\author{
Marina Rodriguez, MD ${ }^{1}$ Ken Heida, MD ${ }^{1}$ Danielle E. Rider, BA ${ }^{2}$ Gens P. Goodman, DO ${ }^{1}$ \\ Brian R. Waterman, $M^{3}$ Philip J. Belmont Jr., MD $^{4}$
}

${ }^{1}$ Department of Orthopaedic Surgery and Rehabilitation, William Beaumont Army Medical Center, El Paso, Texas

${ }^{2}$ Wake Forest School of Medicine, Winston-Salem, North Carolina

3 Division of Sports Medicine, Department of Orthopaedic Surgery, Wake Forest School of Medicine, Winston-Salem, North Carolina

${ }^{4}$ Department of Surgery, Uniformed Services University of the Health Sciences, Bethesda, Maryland

J Knee Surg 2022;35:1393-1400.

\begin{abstract}
Address for correspondence Brian R. Waterman, MD, Division of Sports Medicine, Department of Orthopaedic Surgery, Wake Forest School of Medicine, 4th Floor, Watlington Hall, Medical Center Boulevard, Winston-Salem, NC 27157-1070

(e-mail: brian.r.waterman@gmail.com).
\end{abstract}

\author{
Abstract \\ Keywords \\ - unicompartmental \\ knee arthroplasty \\ - work \\ - military \\ - occupation \\ - functional outcomes
}

This study evaluates return to work and revision rates for medial unicondylar knee arthroplasty (UKA) in a high-demand military cohort. Patient demographic and clinical variables were isolated from the medical records of active-duty military servicemembers with at least 2 years of postoperative follow-up and correlated with return to work, medial UKA survivorship, and perioperative complications. The medial UKA annual revision rate was calculated as the percentage of implants revised per observed component year. A total of 39 servicemembers underwent 46 primary medial UKAs ( 32 unilateral and 7 bilateral) with a mean follow-up of $3.9(2.0-6.6)$ years. At a minimum of 2 years postoperatively, 33 (85\%) servicemembers returned to military service or successfully completed their service obligation. Older servicemembers (odds ratio $[O R]=0.67 ; 95 \%$ confidence interval $[\mathrm{Cl}]: 0.45,0.99)$ had a significantly decreased OR for knee-related medical separation. Nine servicemembers (20\%) had conversion to TKA at an average of 2.4 (range, 0.6-5.6) years with a medial UKA annual revision rate of $5 \%$. When compared with Navy/Air Force, Army/Marine servicemembers had an increased TKA conversion rate $(\mathrm{OR}=5.40 ; 95 \% \mathrm{Cl}$ : 1.13, 25.81). Older age decreased the likelihood of medical separation and Army/Marines service was the sole risk factor associated with conversion to TKA. The level of evidence is IV, therapeutic case series.
Osteoarthritis (OA) is a chronic degenerative condition that can result in severe knee pain, functional limitations, and disability. ${ }^{1,2}$ It can occur throughout the knee or be isolated to a single compartment of the knee. Participation in sports, impact activities, and heavy labor are reported risk factors for the development of $\mathrm{OA}$ of the knee and subsequent primary knee replacement. ${ }^{3-8}$ Military servicemembers pose a unique population given their young age and high

received

April 29, 2020

accepted after revision

January 2, 2021

published online

February 19, 2021 level of physical and occupational demands. Compared with age-matched groups, they have increased rates and earlier onset of lower extremity OA..$^{9,10} \mathrm{OA}$ and posttraumatic OA, particularly of the knee, remain among the leading sources of medical disability and subsequent military discharge among servicemembers. $^{11-13}$

While generalized OA of the knee has been successfully treated with total knee arthroplasty (TKA), arthritis localized (c) 2021. Thieme. All rights reserved. Thieme Medical Publishers, Inc., 333 Seventh Avenue, 18th Floor, New York, NY 10001, USA
DOI https://doi.org/ 10.1055/s-0041-1723968. ISSN 1538-8506. 
to a single compartment can be managed through the unicondylar knee arthroplasty (UKA). Proposed benefits of medial UKA include less invasive approach, quicker recovery time, less pain, and better functional outcomes when compared with either $\mathrm{TKA}^{14-21}$ or high tibial osteotomy (HTO). ${ }^{22-24}$ However, there is limited information detailing the outcomes in a younger patient demographic, particularly as it relates to an ability to return to work. Medial UKA has demonstrated a threefold increase in utilization, ${ }^{25,26}$ especially as an intermediate surgical treatment option for patients younger than 55 years. ${ }^{27}$ Given that younger patients are more prone to return to higher occupational demands and recreational athletic activities, early wear and high revision rates remain concerning for medial UKA. These factors may also have important cost implications and increased rates of complications more commonly associated with revision knee arthroplasty surgery ${ }^{28-30}$ in spite of improved mid-term medial UKA survivorship at high-volume centers. ${ }^{31,32}$

Return to sporting activity is reported to occur at a higher rate with UKA versus TKA; however, both procedures demonstrate a decrease in return to high impact activities with patients favoring low impact sports. ${ }^{33-35}$

To our knowledge, the surgical outcomes of medial UKA within a high-demand, athletic military cohort were previously assessed through limited sampling as a part of a larger overarching study detailing joint arthroplasty in military servicemembers. ${ }^{36}$ The purpose of this study was to determine rates for return to work and revision in a large-homogeneous, active population after medial UKA with a minimum 2 years of followup. We hypothesize that medial UKA in a cohort of military servicemembers allows them to reliably return to previous lower extremity function.

\section{Methods}

After Institutional Review Board approval, all active-duty military servicemembers undergoing a medial UKA (Current Procedural Terminology code 27446) for the established diagnosis of knee OA International Classification of Disease, Ninth Revision, 715.16 between January 2008 and December 2012 were identified using the Military Health System Management Analysis and Reporting Tool database. Exclusion criteria included nonactive duty beneficiaries, individuals with less than 2 years of clinical follow-up, and instances of miscoding.

The U.S. Department of Defense electronic health record (Armed Forces Health Longitudinal Application [Version 3.3]) was examined to confirm the accuracy of procedural coding of the index medial UKA procedure and to record laterality, body mass index (BMI), branch of military service, tobacco use, unilateral versus bilateral medial UKA, secondary surgical procedures, and commencement of a medical discharge due to chronic, rate-limiting knee issues. Additionally, fellowship training and subspecialty of the surgeon was evaluated. The medial UKA annual revision rate was calculated as the percentage of implants revised per observed component year. ${ }^{37}$ Groups were determined by rank, including enlisted servicemember (E1 [private]-E9 [sergeant major]) and officer (WO1 [warrant officer]-06 [colonel]).
The outcomes of interest were the ability to return to military occupation 2 years or more after medial UKA and conversion of a medial UKA to a TKA. The standards for medical fitness are detailed within the regulations of the Air Force, Army, and Navy and include the occupational requirements of all military servicemembers. ${ }^{38-40}$ These regulations are specific to each branch of the military, but commonly entail passing a semiannual physical fitness test that includes a timed aerobic event and adhering to weight and body composition standards. The Physical Profile (DA 3349) within the e-Profile electronic profiling system (Version 3.17, Medical Operational Data System, Falls Church, VA) is utilized to document all physical duty limitations in addition to final medical separations. All military servicemembers with an authenticated initiation of a knee-related medical separation after medial UKA were identified and cross-referenced to confirm the cause of separation using the electronic medical record, U.S. Physical Disability Agency Database, and the e-Profile system.

Univariate analysis was used to determine the association between the independent patient demographic and surgical variables (listed in - Tables 1 and $\mathbf{2}$ ) and the outcomes of a servicemember being medically separated (-Table $\mathbf{1}$ ) or undergoing a conversion to a TKA (-Table 2) following medial UKA. Variables found to have a $p$-value of $<0.2$ were utilized in the multivariate analysis. Significant independent predictor variables were established as those that sustained $p$-values $<0.05$ with odds ratio (OR) and $95 \%$ confidence interval $(\mathrm{CI})$ exclusive of 1 . All statistical analyses were performed with the use of SAS software, Version 9.4 (SAS Institute, Cary, NC).

The modest sample size of the present study $(N=39)$ may have limited the significance of the conducted statistical comparisons. To assess this, a post hoc power analysis was conducted with $G^{*}$ Power 3.1.9.7 (Erdfelder, Faul, \& Buchner, 1992). The calculated power $(1-\beta)$ ranged between 0.32 and 0.81 for older servicemembers with decreased OR for military separation and Army or Marine with increased OR for TKA conversion, respectively. Thus, the required sample size to achieve a desired power of 0.80 was calculated as 180 . It is likely that our negative findings can be partially attributed to a limited sample size.

\section{Results}

\section{Demographics}

There were a total of 46 consecutive medial UKA procedures, including 32 unilateral and 7 bilateral staged medial UKAs, identified among 39 active-duty U.S. military servicemembers during the study period. The mean patient age at the time of surgery was 44.5 (standard deviation [SD] 5.6, range 36-60) years, while the average BMI was 29.0 (SD 3.3, range 23.1$36.3 \mathrm{~kg} / \mathrm{m}^{2}$ ). The majority of patients were male (95\%), did not use tobacco $(77 \%)$, were $<45$ years old $(62 \%)$, were enlisted rank group (63\%), had a $\mathrm{BMI}<30(62 \%)$, and underwent a unilateral medial UKA (82\%). The mean follow-up from the time of surgery was 3.9 (SD 1.3; range, 2.0-6.6) years. Those patients who underwent bilateral staged medial UKAs had an average time interval of 18.9 (SD 12.8, range 7-45) months 
Table 1 Risk factors for medical separation following medial unicondylar knee arthroplasty in military servicemembers

\begin{tabular}{|c|c|c|c|c|c|}
\hline & $N(\%)$ & $\begin{array}{l}\text { Medical } \\
\text { separation }\end{array}$ & $\begin{array}{l}\text { No medical } \\
\text { separation }\end{array}$ & $\begin{array}{l}\text { Odds ratio } \\
\text { (95\% Cl) }\end{array}$ & $p$-Value \\
\hline Age, mean $\pm S D(y)$ & $44.5 \pm 5.6$ & $40.7 \pm 1.6$ & $46.0 \pm 5.7$ & $0.67(0.45,0.99)$ & 0.0434 \\
\hline Age $<45$ & $24(62 \%)$ & $6(30 \%)$ & $14(70 \%)$ & Referent & 0.0918 \\
\hline Age $\geq 45$ & $15(38 \%)$ & $0(0 \%)$ & $15(100 \%)$ & $0.07(0.01,1.53)$ & \\
\hline \multicolumn{6}{|l|}{ Sex } \\
\hline Male & 37 (95\%) & $6(18 \%)$ & $27(82 \%)$ & $1.18(0.03,53.86)$ & 0.9316 \\
\hline Female & $2(5 \%)$ & $0(0 \%)$ & $2(100 \%)$ & Referent & \\
\hline $\begin{array}{l}\text { BMI } \\
\text { Mean } \pm \text { SD }\end{array}$ & $29.0 \pm 3.3$ & $27.4 \pm 2.1$ & $29.0 \pm 3.6$ & $0.85(0.63,1.16)$ & 0.3025 \\
\hline $\mathrm{BMI}<30$ & $24(62 \%)$ & $5(21 \%)$ & $19(79 \%)$ & Referent & \\
\hline $\mathrm{BMI} \geq 30$ & $15(38 \%)$ & $1(9 \%)$ & $10(91 \%)$ & $0.38(0.04,3.71)$ & 0.4054 \\
\hline \multicolumn{6}{|l|}{ Tobacco use } \\
\hline Yes & $9(23 \%)$ & $3(38 \%)$ & $5(62 \%)$ & $4.80(0.74,31.08)$ & 0.0998 \\
\hline No & $30(77 \%)$ & $3(11 \%)$ & $24(89 \%)$ & Referent & \\
\hline \multicolumn{6}{|l|}{ Servicemember population } \\
\hline Enlisted (E1-E9) & $22(63 \%)$ & $5(28 \%)$ & $13(72 \%)$ & $11.00(0.50,244.46)$ & 0.1297 \\
\hline Warrant officer/officer (W01-06) & $13(37 \%)$ & $0(0 \%)$ & $13(100 \%)$ & Referent & \\
\hline \multicolumn{6}{|l|}{ Branch of service } \\
\hline Army/Marines & $15(38 \%)$ & $2(14 \%)$ & $12(86 \%)$ & $0.71(0.11,4.51)$ & 0.7151 \\
\hline Navy/Air Force/other & $24(62 \%)$ & $4(19 \%)$ & $17(81 \%)$ & Referent & \\
\hline \multicolumn{6}{|l|}{ Bilateral procedure } \\
\hline Yes & $7(18 \%)$ & $0(0 \%)$ & $6(100 \%)$ & $0.28(0.01,7.03)$ & 0.4374 \\
\hline No & $32(82 \%)$ & $6(21 \%)$ & $23(79 \%)$ & Referent & \\
\hline \multicolumn{6}{|l|}{ Fellowship surgeon } \\
\hline Yes & $22(56 \%)$ & $2(10 \%)$ & $18(90 \%)$ & $0.31(0.05,1.95)$ & 0.2105 \\
\hline No & $17(44 \%)$ & $4(27 \%)$ & $11(73 \%)$ & Referent & \\
\hline
\end{tabular}

Abbreviations: BMI, body mass index; $\mathrm{Cl}$, confidence interval; SD, standard deviation.

between staged procedures. Details regarding the number of servicemembers at each stage are provided in -Figs. 1 and 2.

\section{Occupational Outcomes}

At minimum occupational follow-up period of 2 years postoperatively, 33 military servicemembers (85\%) had returned to full active duty service or fulfilled their remaining service obligations, while $6(15 \%)$ were medically separated secondary to persistent, rate-limiting knee symptoms (-Table 1). The mean time for servicemembers undergoing a medical separation was 1.4 (SD 0.4, range 0.9-1.7) years from the index medial UKA. Univariate analysis revealed that older military servicemembers $(\mathrm{OR}=0.67$ per annual increase in patient age; $95 \% \mathrm{CI}: 0.45,0.99)$ had a significantly decreased OR for being medically separated following a medial UKA (-Table $\mathbf{1}$ ).

\section{Surgical Outcomes and Rates of Revision}

Of the 46 medial UKAs, there were a total of nine conversion to TKA procedures (20\%) performed at an average of 2.4 (SD 1.7, range 0.6-5.6) years (- Table 2). No other revision procedures were performed. The calculated annual revision rate was $5.0 \%$.
Among the nine servicemembers who underwent a TKA conversion, all were aseptic and none was medically separated from military service. The indications for the medial UKA to TKA conversions included progression of OA (56\%), persistent pain (22\%), component loosening (11\%), and component malposition (11\%). Univariate analysis demonstrated an increased rate of TKA conversion following a medial UKA in Army or Marine servicemembers ( $\mathrm{OR}=5.40 ; 95 \% \mathrm{CI}: 1.13,25.81)$ when compared with Navy or Air Force servicemembers (-Table 3).

\section{Discussion}

The current investigation sought to evaluate the surgical outcomes and revision rates of medial UKA within an active military cohort. The physical demands of servicemembers are stratified by workload, with medium demands defined as occasionally lifting more than 80 pounds and consistently lifting 40 pounds or more. ${ }^{41}$ As such, this study offers unique insights about the functional results of patients returning to the rigorous physical fitness and distinct occupational demands required of medium to heavy labor military service. 
Table 2 Risk factors for conversion to total knee arthroplasty following medial unicondylar knee arthroplasty in military servicemembers by procedure $(N=46)$

\begin{tabular}{|c|c|c|c|c|c|}
\hline & $N(\%)$ & $\begin{array}{l}\text { Medical } \\
\text { separation }\end{array}$ & $\begin{array}{l}\text { No medical } \\
\text { separation }\end{array}$ & $\begin{array}{l}\text { Odds ratio } \\
(95 \% \mathrm{Cl})\end{array}$ & $p$-Value \\
\hline Age, mean \pm SD (y) & $44.4 \pm 5.3$ & $46.6 \pm 7.6$ & $43.8 \pm 4.5$ & $1.10(0.96,1.25)$ & 0.1712 \\
\hline Age $<45$ & $29(63 \%)$ & $5(17 \%)$ & $24(83 \%)$ & Referent & \\
\hline Age $\geq 45$ & $17(37 \%)$ & $4(24 \%)$ & $13(76 \%)$ & $1.48(0.34,6.48)$ & 0.605 \\
\hline \multicolumn{6}{|l|}{ Sex } \\
\hline Male & $44(96 \%)$ & $9(20 \%)$ & $35(80 \%)$ & $1.34(0.03,59.19)$ & 0.8801 \\
\hline Female & $2(4 \%)$ & $0(0 \%)$ & $2(100 \%)$ & Referent & \\
\hline $\begin{array}{l}\text { BMI } \\
\text { Mean } \pm \text { SD }\end{array}$ & $29.2 \pm 3.4$ & $30.6 \pm 3.2$ & $28.9 \pm 3.4$ & $1.17(0.94,1.45)$ & 0.1678 \\
\hline $\mathrm{BMI}<30$ & $29(63 \%)$ & $5(17 \%)$ & $24(83 \%)$ & Referent & \\
\hline $\mathrm{BMI} \geq 30$ & $17(37 \%)$ & $4(24 \%)$ & $13(76 \%)$ & $1.48(0.34,6.48)$ & 0.605 \\
\hline \multicolumn{6}{|l|}{ Tobacco use } \\
\hline Yes & $10(22 \%)$ & $2(20 \%)$ & $8(80 \%)$ & $1.04(0.18,5.99)$ & 0.9686 \\
\hline No & $36(78 \%)$ & $7(19 \%)$ & $29(81 \%)$ & Referent & \\
\hline \multicolumn{6}{|l|}{ Servicemember population } \\
\hline Enlisted (E1-E9) & $27(66 \%)$ & $3(11 \%)$ & $24(89 \%)$ & $0.31(0.06,1.66)$ & 0.1719 \\
\hline Warrant officer/officer (WO1-O6) & $14(34 \%)$ & $4(29 \%)$ & $10(71 \%)$ & Referent & \\
\hline \multicolumn{6}{|l|}{ Branch of service } \\
\hline Army/Marines & $16(35 \%)$ & $6(38 \%)$ & $10(62 \%)$ & $5.40(1.13,25.81)$ & 0.0346 \\
\hline Navy/Air Force/other & $30(65 \%)$ & $3(10 \%)$ & $27(90 \%)$ & Referent & \\
\hline \multicolumn{6}{|l|}{ Bilateral procedure } \\
\hline Yes & $14(30 \%)$ & $2(14 \%)$ & $12(86 \%)$ & $0.28(0.01,7.03)$ & 0.5534 \\
\hline No & $32(70 \%)$ & $7(22 \%)$ & $25(78 \%)$ & Referent & \\
\hline \multicolumn{6}{|l|}{ Fellowship surgeon } \\
\hline Yes & $25(54 \%)$ & $7(28 \%)$ & $18(72 \%)$ & 3.69. $(0.68,20.19)$ & 0.1316 \\
\hline No & $21(46 \%)$ & $2(10 \%)$ & 19 (90\%) & Referent & \\
\hline
\end{tabular}

Abbreviations: BMI, body mass index; $\mathrm{Cl}$, confidence interval; SD, standard deviation.

While our study found that the majority of patients undergoing medial UKA remained on active duty or completed their term of service, there was a high rate of conversion to TKA.

Given the twofold increase in knee arthroplasty among patients younger than 50 years, ${ }^{42}$ it is important to assess return to gainful employment. While previous medial UKA studies have identified successful return to work as an important and underevaluated metric in patient-centered outcomes, these reports have not adequately addressed patients with moderateto high-occupational demands. The reported rates of return to preoperative employment after medial UKA range from 82 to $91 \%$ in civilian patients. However, these studies have several shortcomings including unspecified average age at index surgery, low-demand or sedentary level of activities, less than 2-year minimum follow-up, lack of preoperative occupational demand classification, and an absence of TKA conversion data. ${ }^{20,43}$ In the present study, $85 \%$ of military servicemembers returned to military function at short-term follow-up. ${ }^{44,45}$ Older servicemembers were at decreased risk (OR 0.67) of medical separation with age analyzed as a continuous variable.
Similar findings were documented by Belmont et al, where servicemembers under 45 years of age were at significantly higher risk of medical separation after TKA. ${ }^{46}$ The inherent occupational demands and performance expectations of younger, more junior ranking servicemembers following knee arthroplasty procedure may offer a plausible explanation for their greater risk of medical separation.

The most common underlying reasons for conversion of UKA to TKA include progression of tibiofemoral arthritis, prosthetic loosening, and persistent knee pain. ${ }^{47}$ While large-scale studies examining more than 8,000 UKAs demonstrate revision rates of 10.5 to $10.9 \%$ at mid-term follow-up, $20 \%$ of medial UKA knees underwent TKA conversion in the current study. ${ }^{48-50}$ These findings are consistent with those of W-Dahl et al, who demonstrated a $20 \%$ revision rate for UKA patients under the age of 55 years. ${ }^{25}$ Ostensibly, younger military servicemembers with high activity levels and longer life expectancy have an increased likelihood for TKA conversion. However, the medial UKA cohort annual revision rate of 5.0\% far exceeds the recommended costeffective annual revision rate threshold of $1.5 \%$ established for 

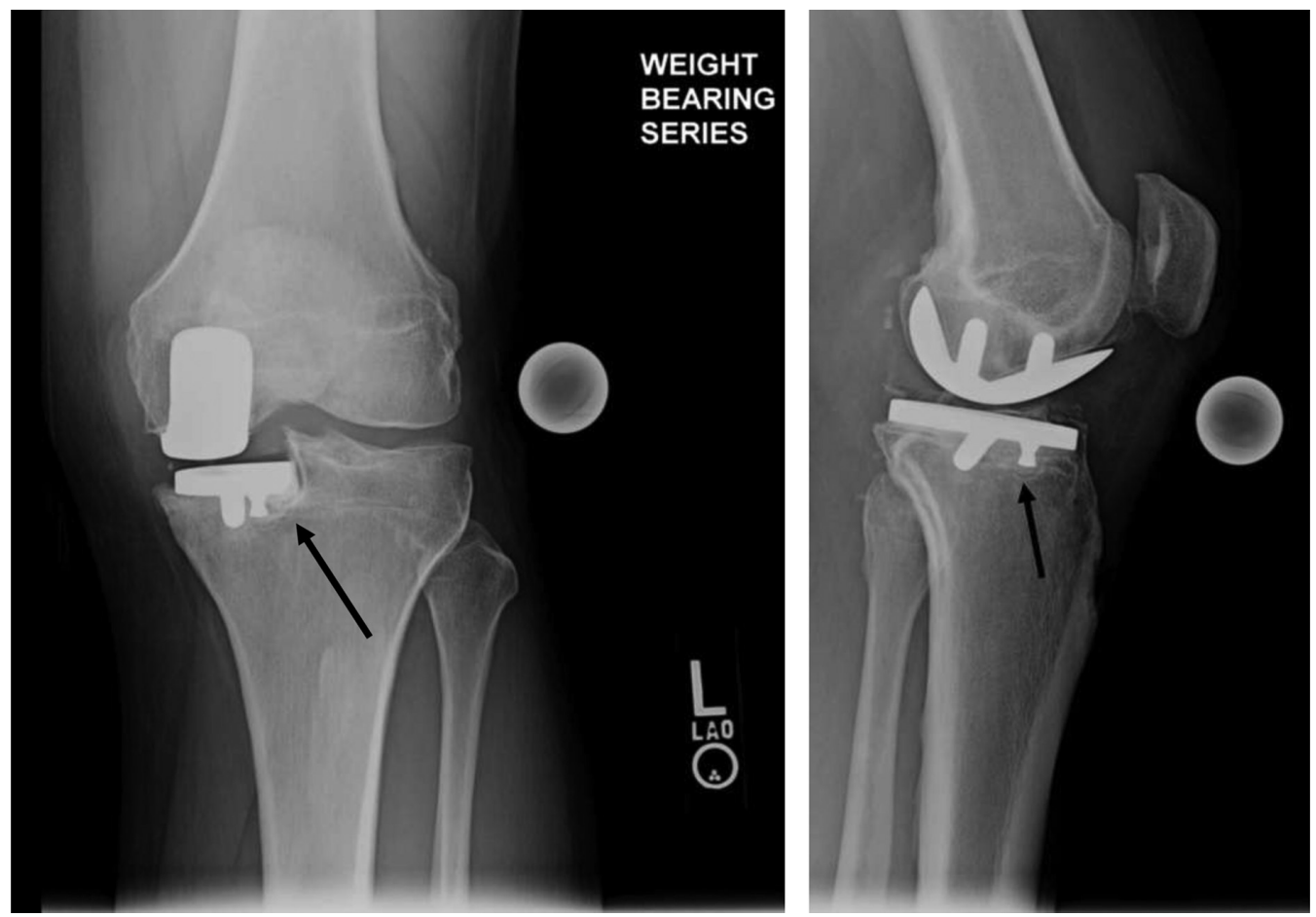

Fig. 1 Number of servicemembers stratified by bilateral versus unilateral procedure and necessity of revision. UKA, unicondylar knee arthroplasty.

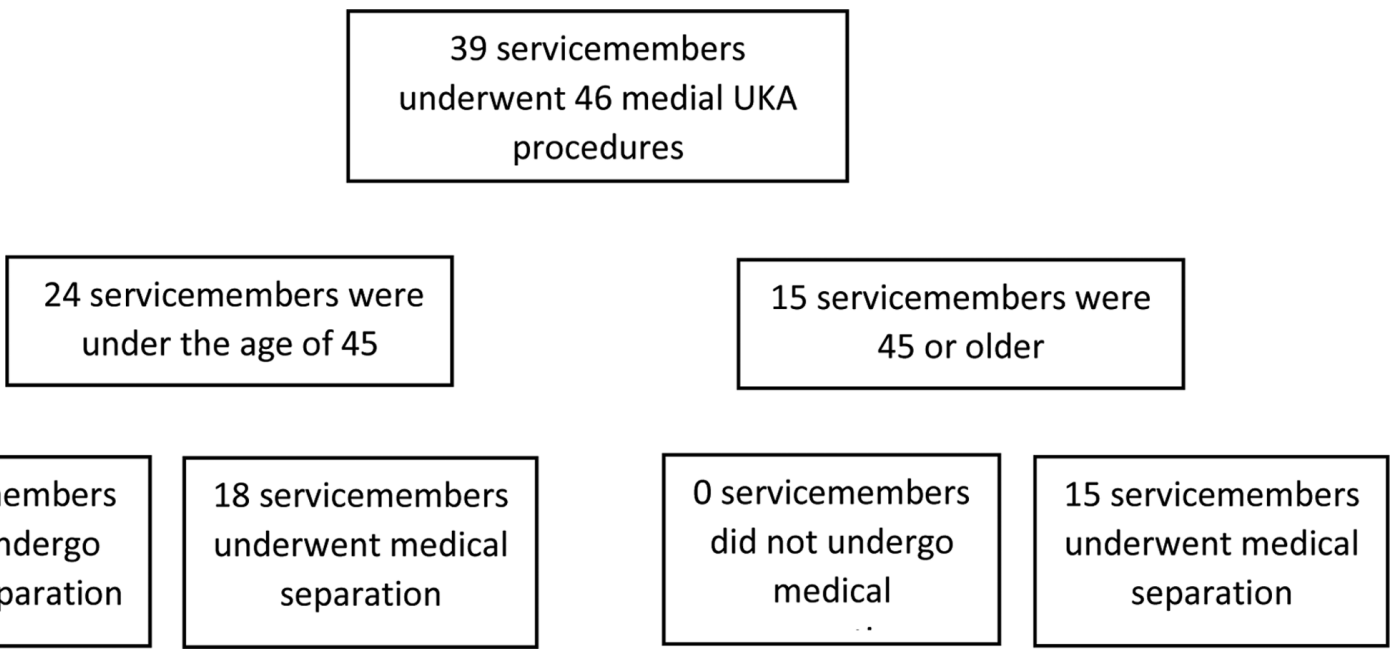

Fig. 2 Number of servicemembers stratified by return to duty versus medical separation. UKA, unicondylar knee arthroplasty.

medial UKA patients $<65$ years. ${ }^{37}$ The sole risk factor associated with TKA conversion $(\mathrm{OR}=5.40 ; 95 \% \mathrm{CI}: 1.13,25.81)$ was service in the Army or the Marine Corps, which typically entails greater physical and occupational demands.

Medial UKA to TKA conversion is associated with inferior surgical outcomes, including revision rates approximately fourfold higher than primary TKA, and patient-reported outcomes similar to those of revision TKA. ${ }^{49,51}$ Consequently, the poorer outcomes associated with conversion of UKA to TKA must be balanced against more conservative and joint-preserving options in younger, more active patient populations. Additional registry data also demonstrate a significantly increased risk of revision following previous medial UKA and previous closed-wedge HTOs compared with primary TKA.
Stemmed or revision arthroplasty implants were required in 17 to $34 \%$ of UKA to TKA conversions compared with $4 \%$ of HTO to TKA conversions. ${ }^{28,50,51}$ These increased revision rates may be due to the high preoperative expectations for knee arthroplasty common in younger and male patients. Patients anticipate significant improvements in ability to perform routine activities of daily living, work, and leisure. ${ }^{52,53}$ Therefore, these medial UKA patients with substantial occupational demands should be preoperatively counseled about return to previous employment, including difficulty kneeling and squatting, potential long-term effects on implant survival, progressive adjacent compartment degeneration, prosthetic complications, possible persistence of knee pain, and the risks and complexities associated with conversion to TKA. 
Table 3 Demographics and indication for conversion to TKA

\begin{tabular}{|l|l|l|l|l|}
\hline Patient & Age & Branch of service & Time until conversion to TKA $(\mathrm{y})$ & Indication for revision \\
\hline 1 & 39 & Air Force & 5.5 & Pain/progression of OA \\
\hline 2 & 55 & Army & 1.6 & Progression of OA \\
\hline 3 & 49 & Army & 4.3 & Progression of OA \\
\hline 4 & 41 & Navy & 1.4 & Component malposition \\
\hline 5 & 39 & Army & 3.0 & Component loosening \\
\hline 6 & 43 & Public Health Service Corps & 3.0 & Progression of OA \\
\hline 7 & 60 & Army & 1.2 & Anterior knee pain \\
\hline 8 & 42 & Army & 0.7 & Persistent pain \\
\hline 9 & 51 & Army & 0.5 & Pain/progression of OA \\
\hline
\end{tabular}

Abbreviations: OA, osteoarthritis; TKA, total knee arthroplasty.

Prospective long-term studies of patients with medial UKA resuming moderate- to high-occupational demand jobs are warranted to better characterize the medical and economic risks vis-à-vis expected pain relief, improved physical function, and psychosocial well-being. ${ }^{54,55}$

The strengths of this study include the closed health care system, universally mandated physical fitness requirements, and intense occupational demands for these active duty servicemembers who underwent medial UKA. However, there are limitations. First, the retrospective study of prospectively gathered data limits the amount of information that can be reliably obtained from preexisting medical records, including patient-reported outcomes. Second, this military cohort's occupational and physical demands are generally nonmodifiable and may be very challenging to perform following medial UKA. Third, servicemembers may be inclined to pursue a disability-associated medical separation to protect themselves from further injury or secondary surgery, as seen in the Workers' Compensation system. ${ }^{56}$

\section{Conclusion}

Medial UKA offers young, highly active military servicemembers a potential option for treatment of isolated medial compartment $\mathrm{OA}$ with $85 \%$ of patients remaining on active duty or completing their term of service. However, patients should be counseled that a persistent high rate of activity, such as that of Army or Marines service, may contribute to a $20 \%$ rate of TKA conversion. Accordingly, these data might be used as a benchmark for assessing occupational outcomes and revision arthroplasty rates for medial UKA or other surgical treatment options for medial tibiofemoral $\mathrm{OA}$ in other active patient populations with increased occupational demands.

\section{Note}

The findings presented in this manuscript have not been previously presented.

\section{Funding}

None.
Conflict of Interest

Some authors are employees of the U.S. federal government and the United States Army. The opinions or assertions contained herein are the private views of the authors and are not to be construed as official or reflecting the views of the Department of Defense or U.S. government.

\section{References}

1 Duncan R, Peat G, Thomas E, Wood L, Hay E, Croft P. How do pain and function vary with compartmental distribution and severity of radiographic knee osteoarthritis? Rheumatology (Oxford) 2008;47(11):1704-1707

2 Sowers M, Karvonen-Gutierrez CA, Jacobson JA, Jiang Y, Yosef M. Associations of anatomical measures from MRI with radiographically defined knee osteoarthritis score, pain, and physical functioning. J Bone Joint Surg Am 2011;93(03):241-251

3 Sandmark H, Vingård E. Sports and risk for severe osteoarthrosis of the knee. Scand J Med Sci Sports 1999;9(05):279-284

4 Spector TD, Harris PA, Hart DJ, et al. Risk of osteoarthritis associated with long-term weight-bearing sports: a radiologic survey of the hips and knees in female ex-athletes and population controls. Arthritis Rheum 1996;39(06):988-995

5 Coggon D, Croft P, Kellingray S, Barrett D, McLaren M, Cooper C. Occupational physical activities and osteoarthritis of the knee. Arthritis Rheum 2000;43(07):1443-1449

6 Ezzat AM, Cibere J, Koehoorn M, Li LC. Association between cumulative joint loading from occupational activities and knee osteoarthritis. Arthritis Care Res (Hoboken) 2013;65(10):1634-1642

7 Muraki S, Oka H, Akune T, et al. Association of occupational activity with joint space narrowing and osteophytosis in the medial compartment of the knee: the ROAD study (OAC5914R2). Osteoarthritis Cartilage 2011;19(07):840-846

8 Wang Y, Simpson JA, Wluka AE, et al. Is physical activity a risk factor for primary knee or hip replacement due to osteoarthritis? A prospective cohort study. J Rheumatol 2011;38(02):350-357

9 Cameron KL, Hsiao MS, Owens BD, Burks R, Svoboda SJ. Incidence of physician-diagnosed osteoarthritis among active duty United States military service members. Arthritis Rheum 2011;63(10): 2974-2982

10 Showery JE, Kusnezov NA, Dunn JC, Bader JO, Belmont PJ Jr, Waterman BR. The rising incidence of degenerative and posttraumatic osteoarthritis of the knee in the United States military. J Arthroplasty 2016;31(10):2108-2114

11 Cross JD, Ficke JR, Hsu JR, Masini BD, Wenke JC. Battlefield orthopaedic injuries cause the majority of long-term disabilities. J Am Acad Orthop Surg 2011;19(Suppl 1):S1-S7 
12 Patzkowski JC, Rivera JC, Ficke JR, Wenke JC. The changing face of disability in the US Army: the Operation Enduring Freedom and Operation Iraqi Freedom effect. J Am Acad Orthop Surg 2012;20 (Suppl 1):S23-S30

13 Schoenfeld AJ, Goodman GP, Burks R, Black MA, Nelson JH, Belmont PJ Jr. The influence of musculoskeletal conditions, behavioral health diagnoses and socio-economic status on injuryrelated outcome in a high-demand population. J Bone Joint Surg Am 2014;96(13):e106

14 Duchman KR, Gao Y, Pugely AJ, Martin CT, Callaghan JJ. Differences in short-term complications between unicompartmental and total knee arthroplasty: a propensity score matched analysis. J Bone Joint Surg Am 2014;96(16):1387-1394

15 Lombardi AV Jr, Berend KR, Walter CA, Aziz-Jacobo J, Cheney NA, Cheney NA. Is recovery faster for mobile-bearing unicompartmental than total knee arthroplasty? Clin Orthop Relat Res 2009; 467(06):1450-1457

16 Lygre SH, Espehaug B, Havelin LI, Furnes O, Vollset SE. Pain and function in patients after primary unicompartmental and total knee arthroplasty. J Bone Joint Surg Am 2010;92(18):2890-2897

17 Lyons MC, MacDonald SJ, Somerville LE, Naudie DD, McCalden RW. Unicompartmental versus total knee arthroplasty database analysis: is there a winner? Clin Orthop Relat Res 2012;470(01):84-90

18 Newman J, Pydisetty RV, Ackroyd C. Unicompartmental or total knee replacement: the 15-year results of a prospective randomised controlled trial. J Bone Joint Surg Br 2009;91(01):52-57

19 van der List JP, Chawla H, Villa JC, Pearle AD. The role of patient characteristics on the choice of unicompartmental versus total knee arthroplasty in patients with medial osteoarthritis. J Arthroplasty 2017;32(03):761-766

20 Walton NP, Jahromi I, Lewis PL, Dobson PJ, Angel KR, Campbell DG. Patient-perceived outcomes and return to sport and work: TKA versus mini-incision unicompartmental knee arthroplasty. J Knee Surg 2006;19(02):112-116

21 Zuiderbaan HA, van der List JP, Khamaisy S, et al. Unicompartmental knee arthroplasty versus total knee arthroplasty: which type of artificial joint do patients forget? Knee Surg Sports Traumatol Arthrosc 2017;25(03):681-686

22 Börjesson M, Weidenhielm L, Mattsson E, Olsson E. Gait and clinical measurements in patients with knee osteoarthritis after surgery: a prospective 5-year follow-up study. Knee 2005;12(02): 121-127

23 Krych AJ, Reardon P, Sousa P, Pareek A, Stuart M, Pagnano M. Unicompartmental knee arthroplasty provides higher activity and durability than valgus-producing proximal tibial osteotomy at 5 to 7 years. J Bone Joint Surg Am 2017;99(02):113-122

24 Stukenborg-Colsman C, Wirth CJ, Lazovic D, Wefer A. High tibial osteotomy versus unicompartmental joint replacement in unicompartmental knee joint osteoarthritis: 7-10-year follow-up prospective randomised study. Knee 2001;8(03):187-194

25 W-Dahl A, Robertsson O, Lidgren L. Surgery for knee osteoarthritis in younger patients. Acta Orthop 2010;81(02):161-164

26 Nwachukwu BU, McCormick FM, Schairer WW, Frank RM, Provencher MT, Roche MW. Unicompartmental knee arthroplasty versus high tibial osteotomy: United States practice patterns for the surgical treatment of unicompartmental arthritis. J Arthroplasty 2014;29(08):1586-1589

27 Biswas D, Van Thiel GS, Wetters NG, Pack BJ, Berger RA, Della Valle CJ. Medial unicompartmental knee arthroplasty in patients less than 55 years old: minimum of two years of follow-up. J Arthroplasty 2014;29(01):101-105

28 Craik JD, El Shafie SA, Singh VK, Twyman RS. Revision of unicompartmental knee arthroplasty versus primary total knee arthroplasty. J Arthroplasty 2015;30(04):592-594

29 Ghomrawi HM, Eggman AA, Pearle AD. Effect of age on costeffectiveness of unicompartmental knee arthroplasty compared with total knee arthroplasty in the U.S. J Bone Joint Surg Am 2015; 97(05):396-402
30 Jonas SC, Shah R, Mitra A, Deo SD. 5-Year cost/benefit analysis of revision of failed unicompartmental knee replacements (UKRs); not "just" a primary total knee replacement (TKR). Knee 2014;21 (04):840-842

31 Baker P, Jameson S, Critchley R, Reed M, Gregg P, Deehan D. Center and surgeon volume influence the revision rate following unicondylar knee replacement: an analysis of 23,400 medial cemented unicondylar knee replacements. J Bone Joint Surg Am 2013;95(08):702-709

32 Liddle AD, Judge A, Pandit H, Murray DW. Determinants of revision and functional outcome following unicompartmental knee replacement. Osteoarthritis Cartilage 2014;22(09): 1241-1250

33 Naal FD, Fischer M, Preuss A, et al. Return to sports and recreational activity after unicompartmental knee arthroplasty. Am J Sports Med 2007;35(10):1688-1695

34 Hopper GP, Leach WJ. Participation in sporting activities following knee replacement: total versus unicompartmental. Knee Surg Sports Traumatol Arthrosc 2008;16(10):973-979

35 Witjes S, Gouttebarge V, Kuijer PP, van Geenen RC, Poolman RW, Kerkhoffs GM. Return to sports and physical activity after total and unicondylar knee arthroplasty: a systematic review and meta-analysis. Sports Med 2016;46(02):269-292

36 Glebus GP, Feather TW, Hsu JR, Gerlinger TL. Return to duty and deployment after major joint arthroplasty. J Arthroplasty 2013; 28(08):1270-1273

37 Chawla H, Ghomrawi HM, van der List JP, Eggman AA, Zuiderbaan HA, Pearle AD. Establishing age-specific cost-effective annual revision rates for unicompartmental knee arthroplasty: a metaanalysis. J Arthroplasty 2017;32(01):326-335

38 Air Force Instruction 48-123: Aerospace Medicine Medical Examination and Standards. Washington, DC: Department of the Air Force; 2009

39 Army Regulation 40-501: Standards of Medical Fitness. Washington, DC: Department of the Army; 2011

40 Medical examinations. In: Manual of the Medical Department (MANMED), NAVMED P-117. Washington, DC: Department of the Navy; 2014

41 Department of the Army Pamphlet 611-21: Military Occupational Classification and Structure. Washington, DC: Department of the Army; 2018

42 Singh JA, Vessely MB, Harmsen WS, et al. A population-based study of trends in the use of total hip and total knee arthroplasty, 1969-2008. Mayo Clin Proc 2010;85(10):898-904

43 Foote JA, Smith HK, Jonas SC, Greenwood R, Weale AE. Return to work following knee arthroplasty. Knee 2010;17(01):19-22

44 Dictionary of Occupational Titles - 4th ed., revised. Washington DCU.S. Department of Labor, Office of Administrative Law Judges1991. Accessed September 12, 2016 at: www.oalj.gov/public/ dot/refernces/dotappc.htm

45 Lombardi AV Jr, Nunley RM, Berend KR, et al. Do patients return to work after total knee arthroplasty? Clin Orthop Relat Res 2014; 472(01):138-146

46 Belmont PJ Jr, Heida K, Keeney JA, Hamilton W, Burks R, Waterman BR. Return to work and functional outcomes following primary total knee arthroplasty in U.S. military servicemembers. J Arthroplasty 2015;30(06):968-972

47 Hubertsson J, Petersson IF, Thorstensson CA, Englund M. Risk of sick leave and disability pension in working-age women and men with knee osteoarthritis. Ann Rheum Dis 2013;72(03):401-405

48 van der List JP, Zuiderbaan HA, Pearle AD, Pearle AD. Why do medial unicompartmental knee arthroplasties fail today? J Arthroplasty 2016;31(05):1016-1021

49 Hang JR, Stanford TE, Graves SE, Davidson DC, de Steiger RN, Miller LN. Outcome of revision of unicompartmental knee replacement. Acta Orthop 2010;81(01):95-98

50 Robertsson $0, \mathrm{~W}$-Dahl A. The risk of revision after TKA is affected by previous HTO or UKA. Clin Orthop Relat Res 2015;473(01):90-93 
51 Pearse AJ, Hooper GJ, Rothwell A, Frampton C. Survival and functional outcome after revision of a unicompartmental to a total knee replacement: the New Zealand National Joint Registry. J Bone Joint Surg Br 2010;92(04):508-512

52 Scott CE, Bugler KE, Clement ND, MacDonald D, Howie CR, Biant LC. Patient expectations of arthroplasty of the hip and knee. J Bone Joint Surg Br 2012;94(07):974-981

53 Witjes S, van Geenen RC, Koenraadt KL, et al. Expectations of younger patients concerning activities after knee arthroplasty: are we asking the right questions? Qual Life Res 2017;26(02):403-417
54 Bardgett M, Lally J, Malviya A, Deehan D. Return to work after knee replacement: a qualitative study of patient experiences. BMJ Open 2016;6(02):e007912

55 Mancuso CA, Graziano S, Briskie LM, et al. Randomized trials to modify patients' preoperative expectations of hip and knee arthroplasties. Clin Orthop Relat Res 2008;466(02):424-431

56 Clyde CT, Goyal N, Matar WY, Witmer D, Restrepo C, Hozack WJ. Workers' Compensation patients after total joint arthroplasty: do they return to work? J Arthroplasty 2013;28(06): 883-887 